\title{
THE EFFECTS OF SERVICE FAILURES TYPES ON SATISFACTION, TRUST, AND INTENTION TO COMPLAIN
}

\section{DOI: 10.17261/Pressacademia.2018.873 PAP- V.7-2018(26)-p.159-164}

\section{Binnaz Cinar ${ }^{1}$, Fatih Koc ${ }^{2}$}

${ }^{1}$ Bandirma Onyedi Eylul University, Sosyal Bilimler Enstitüsü, Bandirma, Balikesir, Turkey. binnazcinar62@gmail.com, ORCID: 0000-0002-0323-9864

${ }^{2}$ Kocaeli University, Kandıra Uygulamalı Bilimler Yüksekokulu, Dış Ticaret ve Avrupa Birliği Bölümü, Kandıra, Kocaeli, Turkey. fatihkoc2004@gmail.com, ORCID: 0000-0002-4751-2340

\section{To cite this document}

Cinar, B., Koc, F. (2018). The effects of service failures types on satisfaction, trust, and intention to complain. PressAcademia Procedia (PAP), V.7, p.159-164.

Permemant link to this document: http://doi.org/10.17261/Pressacademia.2018.873

Copyright: Published by PressAcademia and limited licenced re-use rights only.

\section{ABSTRACT}

Purpose- Service failures are one of prominent determinants of customer dissatisfaction. Service failures can occur in any service. In this study, service failures have been addressed within banking sector. Main purpose of this study is to determine how service failures experienced by small businesses who buy services in the banking sector affect satisfaction, trust, and intention to complain. Beside, the effect levels between these variables were examined through a model. Another purpose of this study is to identify whether satisfaction, trust, and intention to complain differ according to service failure types.

Methodology- In order to achive these purposes, the data was collected from small business serviced by the banks in Bandırma district at Balikesir province. Data collection methods are scenario and questionnaire techniques. Approximately 100 questionnaires were collected for each service failure types and total 302 questionnaires were obtained.

Findings- As a result of the analyses, for every service failure types, it has been found that satisfaction affects trust positively and strongly, trust affects intention to complain negatively and satisfaction has not effect on intention to complain. Furthermore, it has been determined that satisfaction, trust, and intention to complain variables don't differ according to service failure types.

Sonuç- As a result of the analyses, for every service failure types, it has been found that satisfaction affects trust positively and strongly, trust affects intention to complain negatively and satisfaction has not effect on intention to complain. Furthermore, it has been determined that satisfaction, trust, and intention to complain variables don't differ according to service failure types.

Keywords: Service failures, satisfaction, trust, intention to complain, banking sector.

JEL Codes: M30, M31

\section{HIZMET HATASI TÜRLERININ MEMNUNIYET, GÜVEN VE ŞIKÂYET ETME NIYETi ÜZERINDEKI ETKISi}

\section{ÖZET}

Amaç- Hizmet hataları müşteri memnuniyetsizliğinin önde gelen belirleyicilerindendir. Hizmet hataları herhangi bir hizmet alanında ortaya çıkabilir. Bu çalışmada hizmet hataları bankacııık sektörü kapsamında ele alınmıştır. Bu çalışmanın temel amacı, bankacılık sektöründe hizmet satın alan küçük işletmelerin yaşadığı hizmet hataları sonucunda memnuniyet, güven ve şikâyet etme niyeti değişkenlerinin nasıl etkilendiğinin belirlenmesidir. Bununla birlikte, bu değişkenler arasındaki ilişkiler bir model yardımı ile incelenmiştir. Bu çalışmanın bir başka amacı ise, bu üç hizmet hatası türüne göre memnuniyet, güven ve şikâyet etme niyeti değişkenlerinin farklılaşıp farklılaşmadığının tespit edilmesidir.

Yöntem- Bu amaçlara ulaşmak için, Balıkesir Bandırma ilçesinde bankacılık sektöründe hizmet alan küçük işletme sahiplerinden ihtiyaç duyulan veriler senaryo tekniği ve anket yöntemi kullanılarak toplanmıştır. Her bir hata türüne göre yaklaşık 100'er anket toplanarak, toplam 302 anket ile analizler yapılmıştır.

Bulgular- Analizler sonucunda, her hata türü için; memnuniyetin güveni pozitif ve güçlü bir şekilde etkilediği, memnuniyetin şikâyet etme niyeti üzerinde bir etkisinin olmadığı tespit edilmiştir. Bunların yanı sıra, her hata türü için, güvenin şikâyet etme niyeti üzerinde anlamlı ancak negatif etkiye sahip olduğu görülmüştür. Ayrıca memnuniyet, güven ve şikâyet etme niyetlerinin hizmet türlerine göre farklılık göstermediği tespit edilmiştir.

Sonuç- Analizler sonucunda, her hata türü için; memnuniyetin güveni pozitif ve güçlü bir şekilde etkilediği, memnuniyetin şikâyet etme niyeti üzerinde bir etkisinin olmadığı tespit edilmiştir. Bunların yanı sıra, her hata türü için, güvenin şikâyet etme niyeti üzerinde anlamlı ancak negatif etkiye sahip olduğu görülmüştür. Ayrıca memnuniyet, güven ve şikâyet etme niyetlerinin hizmet türlerine göre farklıık göstermediği tespit edilmiştir.

Anahtar Kelimeler: Hizmet hataları, memnuniyet, güven, şikâyet etme niyeti, bankacılık sektörü. JEL Kodları: M30, M31 


\section{GiRiş}

Hizmet hataları, işletmelerin sundukları hizmet performansının müşteri beklenti ve isteklerinin altında hizmet almaları neticesinde, memnun olmamalarından kaynaklanmaktadır (Loo, Boo, \& Khoo-Lattimore, 2013). Hizmetin birden fazla boyuta sahip olması, bu hataların meydana gelmesindeki sebebi oluşturmaktadır (Hoffman \& Kelley, 2003, s. 323). Hizmet hatalarının meydana gelmesi normal bir durum sayılırken, bu hataların telafisinin yapılmaması ve stratejilerin uygulanamaması doğal bir durum değildir. Hizmet hataları meydana geldiğinde işletmeler zorunlu olarak telafi stratejileri uygulamalılardır (Cengiz, Akdu, \& Bostan, 2015, s. 88). Farklı hizmet uygulamaları kapsamında geliştirilen çalışmalar sonucunda, hizmet hatalarının sınıflandırılma türleri (Bitner, Booms, \& Tetreault, 1990) tarafından üç farklı şekilde sınıflandırılmıştır. Bu sınıflandırmaya göre hizmet hatası türleri; ürün hatası/ hizmet sunum sistemi, çalışanlardan kaynaklı hatalar ve müşteri istek ve ihtiyaçlarına yönelik yapılan hatalar şeklinde sıralanmaktadır. Literatürdeki araştırmalar incelendiğinde, üç hata tipinin memnuniyet, güven ve şikâyet etme niyetini nasıl etkilediği, ayna anda örgütlerarası pazarda ve bankacılık sektörü özelinde ele alan bir başka çalışmaya rastlanılmamıştır. Buradan yola çıkarak, bu boşluğu doldurmak ve yazına katkı sağlamak için bu çalışma gerçekleştirilmiştir.

\section{MEMNUNIYET, GÜVEN VE ŞiKAYET ETME NIYETiNE iLIŞKin LiTERATÜR INCELEMESi}

Müşteri memnuniyeti, müşterinin ürün ve hizmetlerden belentilerini elde etmenin verdiği olumlu duyguları açıklayan psikolojik bir kavramdır (Valenzuela \& Vasquez-Parraga, 2006; Bulut, 2011). Bankacılık sektöründe bir pazarlama stratejisi olarak belirtilen müşteri memnuniyeti, yöneticiler tarafından göz önünde bulundurulması gereken önemli bir kavramdır. Dolayısıyla son zamanlarda bankaların memnuniyet kavramının üzerinde durmasına sebep olmaktadır (Khattak \& Kashif-Ur-Rehman, 2010). Bu sebeple, rekabet yoğunluğunun fazla olduğu bankacılık sektöründe, müşterilerin bankalarına karşı göstermiş oldukları sadakatlarının devam etmesi aynı zamanda bankaların yeni müşteriler sağlaması için müşteri memnuniyeti önemli bir rol oynamaktadır (Kaytancı, Ergeç, \& Toprak, 2013). Güven, farklı alanlarda araştırılmış olması sebebiyle pek çok farklı tanımı bulunmaktadır. Güven kavramına yönelik yapılan tanımlamalarda bir konsensus sağlanamamasına rağmen, güvenin kişilerin davranışları üzerindeki etkilerine ilişkin ortak bir fikir birliğine varılmıştır (Hosmer, 1995, s. 380). Bu tanımlamalardan bir kısmı güveni genel, bir kısmı işletme içerisindeki ilişki, diğer bir kısmı ise işletme düzeyinde tanımlanmaktadır. Bu tanımların genelindeki ortak nokta, güvenen ve güvenilen iki tarafın olmasıdır. Hizmet pazarlaması üzerine gerçekleştirilen araştırmalarda, işletme ve müşteri arasındaki ilişkide güvenin önemli bir role sahip olduğu ifade edilmektedir. Hizmetleri denemeden satın alan müşteriler için etkili bir hizmet pazarlaması, güvenin ortaya çıkmasına bağlıdır (Morgan \& Hunt, 1994). Şikâyet, hâksız bir şekilde yapılan iş ya da adil olmayan durumlarla karşılaşan müşterinin satın olmuş olduğu hizmet sonucunda yaşadığı hayal kırıklıklarını ifade etmektedir (Fornell \& Westbrook, 1979, s. 105). Müşteriler tarafından incelenen şikâyet etme niyeti, olumsuz tepkilerden ortaya çıkmaktadır (Singh, 1988, s. 9597). Müşteri şikâyet etme niyeti sekiz temel alanda toplanmaktadır; şikâyet sonrası müşteri davranışlarının belirleyicileri, müşteri şikâyet davranışının teorik ve metodolojik alt yapısı, ürün ya da hizmetten memnun kalmayan müşterilerin verdikleri çeşitli reaksiyonlar ve tepkiler, karşılaşılan sorun ve şikâyetlerin konu ve içerikleri, müşterileri şikâyet etme eylemine yönlendiren faktörler, etkin şikâyet yönetimi ve müşteri şikâyet davranışının kültürler arası analizi ve şikâyette bulunan müşterilerin profilleridir (Ayaz \& Torlak, 2011, s. 83).

Literatürde bankacılık sektöründe hizmet hatalarını inceleyen bir çok çalışma (Lewis \& Spyrakopoulos, 2001; Mishra \& Munjal, 2013; Bell \& Zemke, 1987; McCollough, Berry, \& Yadav, 2000; Öztürk, 2008; Goodwin \& Ross, 1992; Malik, 2012) vardır. Bu çalışmalarda hizmet hatalarının müşteriler tarafından nasıl algılandığı ve hataların memnuniyeti olumsuz etkileyerek şikayet etme niyetlerine neden olduğu tespit edilmiştir. Bu bilgiler neticesinde, hipotezler ve model aşağıda sunuluştur:
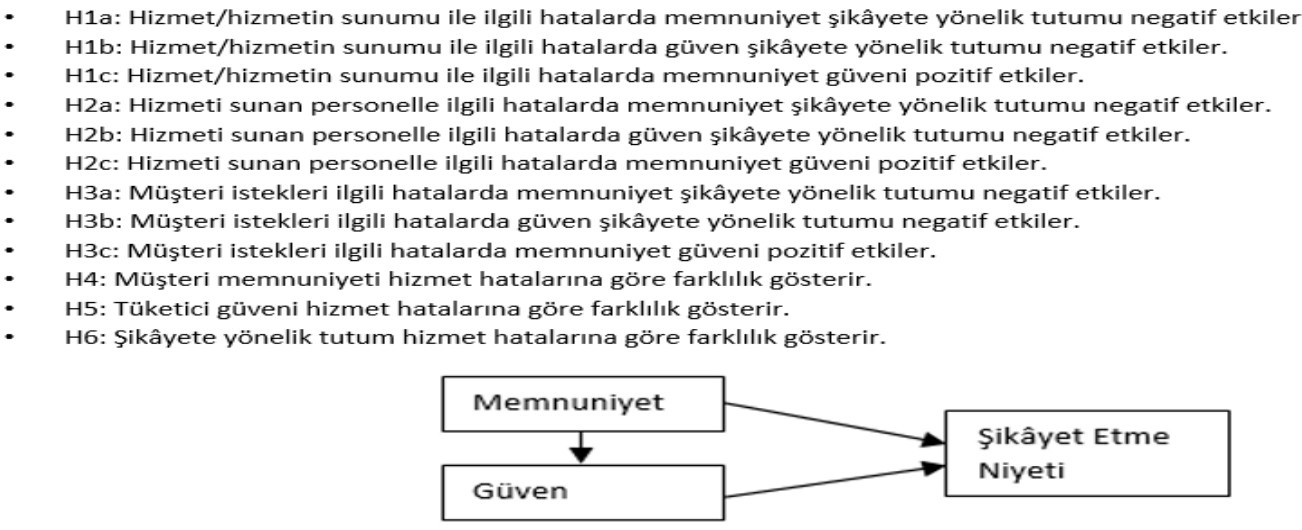

Şekil 1. Araştırmanın Modeli

\section{YÖNTEM}

Bu araştırma, Balıkesir Bandırma ilçesinde faaliyette bulunan küçük işletmelerin hizmet aldıkları bankalar ve karşılaştıkları hizmet hata türlerinin memnuniyet, güven ve şikâyet etme niyeti değişkenleri açısından incelenmek üzere tasarlanmıştır. Her hata türü için üç ayrı anket formu hazırlanıp, anket yöntemi ve senaryo tekniği kullanılarak, Şubat 2018 tarihinde yaklaşık 100 küçük işletme ve toplam 302 küçük işletmeden veriler toplanmıştır. Araştırmada kullanılan memnuniyet ölçeği 5 ifade (Swaen \& Chumpitaz, 2008); güven ölçeği (Suh \& Han, 2002) çalışmasından elde edilmiştir ve 6 ifadeden oluşmaktadır. Son olarak, şikâyet etme niyeti ölçeği ise, (Ayaz \& Torlak, 2011) yılındaki çalışmadan elde edilmiştir ve 3 ifade ankete dâhil edilmiştir. 


\section{BULGULAR}

Bu bölümde öncelikle araştırmanın amaçlarına yönelik, senaryoların cevaplayııılar tarafından nasıl algılandığı belirlemek için cevaplayıcılara iki farklı soru sorulmuştur. Hizmet sunumu ile ilgili hata formunda (\%85 evet, \%15 hayır), hizmeti sunan personel ile ilgili hata formunda (\%84,2 evet, \%15,8) ve müşteri istekleri ile ilgili formunda (\%86,1 evet, \%12,9 hayır) her iki soruda da, verilen senaryoda bir hizmet hatası olduğu ve bu hataların kendileri için önemli olduğu sonucuna ulaşılmıştır.

\subsection{Demografik Bulgular}

Araştırmaya en fazla katılan cevaplayıııların \%31,3'ü kadın, \%68,7'si erkek ve \%69'u evli \%31'i bekar; cevaplayıııların \%57,4'ü 40-59 yaş oranına; katılımcıların \%39,8'i lisans eğitim düzeyinde; cevaplayıcıların \%40,5'i 9001-25000 aylık ciroya; \%90,3'ü 1-6 çalışan sayısına; bankalar ile çalışmaları \%50,7'si 1-6 süre aralığındadır. Cevaplayıııların hizmet aldıkları banka ve hizmet verilen sektörlere ilişkin bilgiler Tablo 1'de verilmiştir.

Tablo 1: Cevaplayıcıların Hizmet Aldıkları Banka ve Hizmet Verdikleri Sektörler

\begin{tabular}{|c|c|c|c|c|c|c|c|c|c|}
\hline $\begin{array}{l}\text { HIZMET } \\
\text { ALINAN BANKA }\end{array}$ & YÜZDE & $\begin{array}{l}\text { HiZMET } \\
\text { BANKA }\end{array}$ & YÜZDE & $\begin{array}{l}\text { HIZMET } \\
\text { VERILEN } \\
\text { SEKTÖR }\end{array}$ & YÜZDE & $\begin{array}{l}\text { HIZMET } \\
\text { VERILEN } \\
\text { SEKTÖR }\end{array}$ & YÜZDE & $\begin{array}{l}\text { HIZMET } \\
\text { VERILEN } \\
\text { SEKTÖR }\end{array}$ & YÜZDE \\
\hline Akbank & 10,9 & Kuveyt Türk Bankası & 4,3 & Ayakkabı & 4,7 & Mobilya & 6,2 & Gıda & 15,0 \\
\hline Denizbank & 11,9 & Vakıfbank & 12,6 & Cep Tel. & 1,9 & Optik & 8,3 & Hed. Eşya & 5,7 \\
\hline Finansbank & 6,0 & Yapı Kredi Bankası & 11,6 & Fotokobi & 4,3 & Petshop & 2,4 & İç Giyim & 4,3 \\
\hline Garanti Bankası & 13,6 & Ziraat Bankası & 9,6 & Eczacı & 6,7 & Tarım & 4,2 & Kasap & 4,2 \\
\hline Halk Bankası & 10,9 & Toplam & 100,0 & Emlak & 4,7 & Kuyumcu & 2,7 & Toplam & 100,0 \\
\hline İş Bankası & 8,6 & & & Tekstil & 24,7 & & & & \\
\hline
\end{tabular}

\subsection{Geçerlilik ve Güvenilirlik Analizi}

Araştırmada kullanılan ölçeklerin geçerliliğini belirlemek için açıklayıcı faktör analizi (AFA) kullanılmıştır. Aşağıda Tablo 2'de geçerlilik ve güvenilirliğine ilişkin analiz sonuçları sunulmuştur.

\section{Tablo 2: Geçerlilik ve Güvenilirlik Analizi}

\begin{tabular}{|c|c|c|c|c|c|c|}
\hline \multirow[b]{2}{*}{ DEĞiŞKENLER } & \multicolumn{3}{|c|}{ FAKTÖRLER } & \multirow[b]{2}{*}{ Özdeğer } & \multirow[b]{2}{*}{$\begin{array}{l}\text { Açıklanan } \\
\text { varyans }\end{array}$} & \multirow[b]{2}{*}{$\begin{array}{l}\text { Cronbach's } \\
\text { Alpha }\end{array}$} \\
\hline & GÜVEN & MEMNUNIYET & $\begin{array}{l}\text { ŞİKÂYET } \\
\text { ETME } \\
\text { NIYETi }\end{array}$ & & & \\
\hline G5 Böyle bir bankaya piyasada güvenilir. & 0,858 & & & & & \\
\hline G6 Böyle bir banka, söz ve yükümlülüklerini yerine getirir. & 0,825 & & & & & \\
\hline G4 Böyle bir bankaya güvenirim. & 0,803 & & & & & \\
\hline $\begin{array}{l}\text { G3 Böyle bir bankanın tavsiyelerinin (yatırım veya bankadan } \\
\text { yeni hizmetler satın alma gibi) yararlı olacağına inanırım. }\end{array}$ & 0,742 & & & 6,260 & 48,151 & 0,909 \\
\hline \multicolumn{7}{|l|}{$\begin{array}{l}\text { G2 Böyle bir banka, denetlenmezse bile, işini doğru şekilde } 0,727 \\
\text { yapar. }\end{array}$} \\
\hline \multicolumn{7}{|l|}{$\begin{array}{l}\text { G1 Böyle bir banka, müşterilerinin çıkarlarını en iyi şekilde } 0,677 \\
\text { korur. }\end{array}$} \\
\hline M5 Bence böyle bir banka iyi bir tercih olacaktır. & & 0,827 & & & & \\
\hline $\begin{array}{l}\text { M2 Böyle bir banka aklıma geldiğinde bende memnuniyet } \\
\text { hissi uyanır. }\end{array}$ & & 0,816 & & & & \\
\hline $\begin{array}{l}\text { M4 Böyle bir bankayı tercih etmenin çok iyi bir fikir olacağını } \\
\text { düşünüyorum. }\end{array}$ & & 0,798 & & 1,624 & 12,494 & 0,891 \\
\hline $\begin{array}{l}\text { M1 Bu bankanın müşterilerinin gereksinimlerini tam anlamıyla } \\
\text { karşılayabileceğini düşünüyorum. }\end{array}$ & & 0,760 & & & & \\
\hline M3 Böyle bir banka, bence, neredeyse en ideal bankadır. & & 0,751 & & & & \\
\hline $\begin{array}{l}\text { SEN2 Bir bankayla böyle bir sorun yaşadığımda, banka } \\
\text { yönetimine ya da personeline memnuniyetsizlik } \\
\text { deneyimimden hemen sonra veya bir sonraki gidişimde } \\
\text { şikâyetimi bildiririm. }\end{array}$ & & & 0,843 & 1,223 & 9,407 & $*$ \\
\hline $\begin{array}{l}\text { SEN3 Bir bankayla böyle bir sorun yaşadığımda, o bankadan } \\
\text { memnuniyetsizliğimin hemen karşılanmasını talep ederim. }\end{array}$ & & & 0,812 & & & \\
\hline $\begin{array}{l}\text { Çıkarım Metodu: Principal Component Analysis. } \\
\text { Döndürme Metodu: Varimax with Kaiser Normalization. } \\
\text { * Ölçek iki ifadeden oluştuğu için alfa değeri hesaplanmamışt } \\
\text { Açıklanan toplam varyans: } 70,052\end{array}$ & & & & & & \\
\hline
\end{tabular}




\subsection{Hipotezlerin Testi}

Öncelikle her hata türü için ele alınan değişkenlerin ortalamaları incelenmiştir ve bu ortalamaların hizmet türüne göre farklılık göstermediği tespit edilmiştir. Dolayısıyla H4, H5 ve H6 hipotezleri reddedilmiştir. Ortalamalara ve varyans analiz sonuçlarına ilişkin sonuçlar Tablo 3'te sunulmuştur. Yapılan regresyon analizi Tablo 4'te sunulmuştur.

Tablo 3: Varyans Analiz Sonuçları ve Hata Türlerine Göre Değişkenlerin Ortalamaları

\begin{tabular}{|c|c|c|c|c|c|}
\hline \multirow{2}{*}{ Değişkenler } & \multirow{2}{*}{ Hata Türleri } & \multirow{2}{*}{$\mathbf{N}$} & \multirow{2}{*}{ Ortalama } & \multicolumn{2}{|c|}{ ANOVA } \\
\hline & & & & $\mathbf{F}$ & Anlamlılık \\
\hline \multirow{3}{*}{ Güven } & Hizmet/Hizmetin Sunumu İle İlgili Hata & 100 & 2,0867 & \multirow{3}{*}{1,999} & \multirow{3}{*}{0,137} \\
\hline & Hizmeti Sunan Personel ile ilgili Hata & 101 & 2,2937 & & \\
\hline & Müşteri İstekleri İle İlgili Hata & 101 & 2,1122 & & \\
\hline \multirow{3}{*}{ Memnuniyet } & Hizmet/Hizmetin Sunumu İle İlgili Hata & 100 & 2,0040 & \multirow{3}{*}{1,468} & \multirow{3}{*}{0,232} \\
\hline & Hizmeti Sunan Personel ile ilgili Hata & 101 & 2,1980 & & \\
\hline & Müşteri İstekleri İle İlgili Hata & 101 & 2,0495 & & \\
\hline \multirow{3}{*}{ Şikâyet Etme Niyeti } & Hizmet/Hizmetin Sunumu İle İlgili Hata & 100 & 3,9000 & \multirow{3}{*}{1.234} & \multirow{3}{*}{0,293} \\
\hline & Hizmeti Sunan Personel ile ilgili Hata & 101 & 3,7970 & & \\
\hline & Müşteri İstekleri İle İlgili Hata & 101 & 3,6683 & & \\
\hline
\end{tabular}

Tablo 4: Regresyon Analizi



Her hata türü için, memnuniyetin güveni pozitif ve güçlü bir şekilde etkilediği; her hata türü için memnuniyetin şikâyet etme niyeti üzerinde bir etkisinin olmadığı ve her hata türü için, güvenin şikâyet etme niyeti üzerinde anlamlı ancak negatif etkiye sahip olduğu görülmüştür. Bu sonuçlara göre $\mathrm{H} 1 \mathrm{a}, \mathrm{H} 2 \mathrm{a}$ ve H3a hipotezleri reddedilmiştir. Ayrıca H1b, H1c, H2b, H2c, H3b ve H3c hipotezleri kabul edilmektedir.

\section{SONUÇ VE ÖNERILER}

Bu çalışma sonucunda, hizmet hatalarının müşteri memnuniyetini, güveni azaltan bir etkiye sahip olduğu ve müşterilerin şikâyet etme niyetini artırdığı bulgusuna ulaşılmıştır. Gerçekleştirilen varyans analizi sonucunda, hata türlerine göre memnuniyet, güven ve şikâyet etme niyetinin değişmediği görülmüştür. Müşteri değerlendirmelerinin olumsuz etkilendiği görülmesine rağmen, değerlendirme ortalamaların birbirine yakın olduğu gözükmektedir. Modele ilişkin analiz sonuçları incelendiğinde, üç hata tipine göre memnuniyetin güveni pozitif bir şekilde etkilediği saptanmıştır. Bu araştırma sonucunda, hataların memnuniyeti azaltıcı etkiye sahip olduğu ve bunun neticesinde güvenin de azaldığını söyleyebiliriz. Bununla birlikte, araştırmanın bir diğer sonucu, hata türlerine göre incelendiğinde güveninin şikâyet etme niyetini negatif etkilediği belirlenmiştir. Güven problemi yaşayan müşterilerin satıcı ya da üretici işletmeye, akrabalarına, eş-dostlarına, tüketici derneklerine, mahkemelere ya da gazetelerin tüketici köşelerine gibi üçüncü gruplara şikâyet etme niyetinde oldukları söylenebilir. Gerçekleştirilen analizlerle birlikte, tüm hata türlerinde memnuniyetin şikâyet etme niyeti üzerinde bir etkisinin olmadığı çalışma sonucunda ulaşılmıştır. Bu durumda müşteriler karşılaştıkları hizmet hataları sonucunda, ileride düzelme olacağını düşündüğü için bir şey yapmama ve sadakatini sürdürmeye devam etmekte, sosyal maliyetler ya da prosedürel maliyetler (çeşitli zorlayıcı sebepler) gibi nedenlerden dolayı hizmet almaya devam etmektedirler ve şikâyet etme niyetleri ortaya çıkmamaktadır (Hirschman, 1970; Landon, 1977; Jones, Reynolds, Mothersbaugh, \& Beatty, 2007).

Bu çalışma ile birlikte, uygulayıcılara ve araştırmacılara çeşitli öneriler sunulmuştur. Müşteriler arasındaki ilişki gücünden faydalanmak isteyen işletmeler, müşterilerin algıladıkları hizmet hatalarının neler oldukları ile ilgili araştırmalar yaparak, müşteri memnuniyetini ve sadakati sağlamayı ve kendilerine olan güven sağlanmalıdır. Böylece müşteriler diğer kişilere şikâyet etme niyetleri ortadan kalkacak ve işletmeden hizmet satın almaya devam edeceklerdir. Bu çalışma Balıkesir Bandırma ilçesinde 302 küçük işletme (esnaf işletmeleri) üzerinde gerçekleştirilmiştir. Farklı yerleşim yerleri, farklı büyüklükteki örneklemlerle ve farklı büyüklükteki firmalarla (KOBi’ler ile) yapılacak yeni araştırmalarla farklı sonuçlar elde edilebilir. 


\section{KAYNAKLAR}

Ayaz, S., Torlak, Ö. (2011). Yüksek hızlı tren (YHT) ile seyahat eden yolcularin şikayet etme niyetini etkileyen faktörler. Tüketim ve Tüketim Araştırmaları Dergisi, 3(2), p. 79-116.

Bamford, D., Wystouri, T. (2005). A case study of service failure and recovery within an international airline. Managing Service Quality: An International Journal, 15(3), p. 306-322.

Bell, C. R., Zemke, R. E. (1987). Service breakdown: the road to recovery, New York.

Bitner, M. J., Booms, B. H., Tetreault, M. S. (1990). The service encounter: diagnosing favorable and unfavorable incidents. Journal of Marketing, 54, p. 71-84.

Bulut, Y. (2011). Otellerde müşteri memnuniyeti ve bir uygulama (Samsun örneği). Uluslararası Sosyal Araştırmalar Dergisi, 4(18), p. 389403.

Cengiz, E., Akdu, S., Bostan, M. K. (2015). Sağlık hizmetlerinde hizmet hatası telafi stratejileri. Gümüşhane Üniversitesi Sosyal Bilimler Elektronik Dergisi(12), p. 87-101.

Chang, H. S., Hsiao, H. L. (2008). Examining the casual relationship among service recovery, perceived justice, perceived risk, and customer value in the hotel industry. The Service Industties Journal, 28(4), p. 513-528.

Duffy, J. A., Miller, J. M., Bexley, J. B. (2006). Banking customers varied reactions to service recovery strategies. International Journal of Bank Marketing, 24(2), p. 112-132.

Fornell, C., Westbrook, R. A. (1979). An exploratory study of assertiveness, aggressiveness and consumer complaning behaviour. Advances in Consumer Research(6), p. 105-110.

Garg, A. (2013). Service recovery paradox in Indian banking industry. The South East Asian Journal of Management, 7(2), p. 23-38.

Goodwin, C. Ross, I. (1992). Consumer responses to service failures: Influence of procedural and interactional fairness perceptions. Journal of Business Research, 25(2), p. 149-163.

Hirschman, A. O. (1970). Exit, voice and loyalty responses to decline in firms. Cambridge: Harvard University Press.

Hoffman, K. D., Kelley, S. W. (2003). A CIT investigation of servicescape failures and associated recovery strategies. Journal of Services Marketing, 17(4)

Hosmer, L. T. (1995). Trust: the connecting link between organizational theory and philosophical ethics. Academy of Management Review, 20(2), p. 379-403.

Jones, M. A., Reynolds, K. E., Mothersbaugh, D. L., Beatty, S. E. (2007). The positive and negative effects of switching costs on relational outcomes. Journal of Service Research, 9, p. 335-355.

Kaytancı, B. G., Ergeç, E. H., Toprak, M. (2013). Katılım bankası müşterilerinde bankacılık ürün ve hizmetlerinde yönelik memnuniyet: Türkiye örneği. SESSION 7C: Sektörel Sorunlar, RUSSIA, p. 801-811.

Keiningham, T. L., Morgeson, F. V., Aksoy, L., Williams, L. (2014). Service failure severity, customer satisfaction, and market share an examination of the airline industry. Journal of Service Research, 17(4), p. 415-431.

Khattak, N. A., Kashif-Ur-Rehman. (2010). Customer satisfaction and awareness of Islamis banking system in Paskistan. African Journal of Business Management, 4(5), p. 662-671.

Komunda, M., Osarenkhoe, A. (2012). Remedy or cure for service failure?: Effects of servive recovery on customer satisfaction and loyalty. Business Process Management Journal, 18(1), p. 82-103.

Landon, L. E. (1977). A model of consumers' complain behaviour. L. E. Landon.

Leong, J. K., Kim, W. G., Ham, S. (2002). The effects of service recovery on repeat patronage. Journal of Quality Assurance in Hospitality \& Tourism, 3(1-2), p. 69-94.

Lewis, B. R., \& Spyrakopoulos, S. (2001). Service failures and recovery in retail banking: the customers' perspective. International Journal of Bank Marketing, 19(1), p. 37-48.

Loo, P. T., Boo, H. C., Khoo-Lattimore, C. (2013). Profiling service failure and customer online complaint motives in the case of single failure and double deviation. Journal of Hospitalit Marketing \& Management, 22(7).

Lorenzoni, N., Lewis, B. R. (2004). Service recovery in the airline industry: a cross- cultural comparison of the attitudes and behavirours of British and Italian front-line personnel. Managing Service Quality: An International Journal, 14(1), p. 11-25.

Malik, G. (2012). Service failure and complaining behavior in Indian banking Industry: a factor analytic study. Quest-Journal of Management and Research, 3(1), p. 45-52.

McCollough, M. A., Berry, L. L., Yadav, M. S. (2000). An empirical investigation of customer satisfaction after service failure and recovery. Journal of Service Research, 3(2), p. 121-137. 
Mishra, S., Munjal, S. (2013). Service failures and complaints in banks. European Journal of Commerce and Management Research, 2(7), 162-167.

Morgan, R. M., Hunt, S. D. (1994). The commitment-trust theory of relationship marketing. Journal of Marketing, 58(3), p. 20-38.

Öztürk, S. A. (2008). Hizmet pazarlaması (8. b). Bursa: Ekin Kitabevi Yayınları.

Rousseau, D. M., Sitkin, S. B., Burt, R. S., Camerer, C. (1998). Not so different after all: a cross-discipline view of trust. Academy of Management Review, 23(3), p. 393-404.

Singh, J. (1988). Consumer Complaint intentions and behavior: definitional and taxonomical issues. Journal of Marketing, 52(1), p. 93-107.

Suh, B., Han, I. (2002). Effect of trust on customer acceptance of internet banking. Electronic Commerce Research and Applications, p. 247263.

Swaen, V., Chumpitaz, R. C. (2008). Impact of corporate social responsibility on consumer trust. Recherche at Applications in Marketing, 23(4), p. 7-33.

Valenzuela, F. A., Vasquez-Parraga, A. (2006). Trust and commitment as mediating variables in the relationship between satiffacton and hotel guest loyalty. Panorama Socio Economico, (32), p. 18-23.

Yang, T. C. (2005). The development of an effective recovery programme after service failures: a case study of restaurants in Glasgow. Tourism and Hospitality Planning \& Development, 18(2), p. 39-54. 